\title{
Tailoring the Mechanical Properties of Laser Cladding-Deposited Ferrous Alloys with a Mixture of 410L Alloy and Fe-Cr-B-Si-Mo Alloy Powders
}

\author{
Sheng Huang ${ }^{1,2}$, Dichen $\mathrm{Li}^{1,2, *}$, Lianzhong Zhang ${ }^{1,2}$, Xiaoyu Zhang ${ }^{1,2}$ and Weijun Zhu ${ }^{1,2}$ \\ 1 State Key Laboratory for Manufacturing Systems Engineering, Xi'an Jiaotong University, Xi'an 710049, \\ China; ahhuangsheng@126.com (S.H.); zhanglianzhong11@sina.com (L.Z.); zhangxiaoyu94@163.com (X.Z.); \\ zhuweijun99@sina.com (W.Z.) \\ 2 School of Mechanical Engineering, Xi'an Jiaotong University, Xi'an 710049, China \\ * Correspondence: dclixjtu@sina.com; Tel.: +86-29-83399510
}

Received: 7 January 2019; Accepted: 24 January 2019; Published: 29 January 2019

\begin{abstract}
The effects of different ratios of 410L alloy and Fe-Cr-B-Si-Mo alloy powders on the microstructure and mechanical properties of laser cladding-deposited ferrous alloys were investigated. The experimental results revealed that the 410L alloy had good strength and excellent ductility due to its microstructure consisting of large elongated ferrite dendrites surrounded by a small number of martensite grains, while the $\mathrm{Fe}-\mathrm{Cr}-\mathrm{B}-\mathrm{Si}-\mathrm{Mo}$ alloy had high strength and poor ductility because of its eutectic microstructure composed of ferrite and $\mathrm{Fe}_{2} \mathrm{~B} / \mathrm{Cr}_{2} \mathrm{~B}$. As the concentration of $\mathrm{Fe}-\mathrm{Cr}-\mathrm{B}-\mathrm{Si}-\mathrm{Mo}$ alloy powder added to the $410 \mathrm{~L}$ alloy powder increased, the ferrite grains became finer and the volume fraction of the eutectic increased, which eventually improved the strength and reduced the plasticity. Then, $410 \mathrm{~L}+12.5 \% \mathrm{Fe}-\mathrm{Cr}-\mathrm{B}-\mathrm{Si}-\mathrm{Mo}$ alloy powder was successfully deposited onto AISI 1060 steel substrate via laser cladding deposition, and the mechanical properties met those of the substrate, which verified that tailoring the mechanical properties of the laser cladding-deposited alloys with a mixture of $410 \mathrm{~L}$ and $\mathrm{Fe}-\mathrm{Cr}-\mathrm{B}-\mathrm{Si}-\mathrm{Mo}$ alloy powders for steel repairing applications is a feasible solution.
\end{abstract}

Keywords: additive manufacturing; laser cladding deposition; 410L alloy; Fe-Cr-B-Si-Mo alloy; microstructure; mechanical properties

\section{Introduction}

Many defective components, which are mis-machined in the manufacturing process or locally worn in the service process, have to be scrapped, resulting in serious resource waste and huge economic losses. Steel is the most commonly used materials for gears, shafts, railway wheels, and so on in many industrial applications, and the market demand for the repairing of such products is huge. Therefore, it is urgently necessary to find an effective repair method to restore the geometry and provide sufficient strength to such components, allowing for their continued use [1].

Laser cladding deposition (LCD), also called laser engineering net shaping (LENS) [2], is a laser additive manufacturing process, which is based on the iterative process of coaxial powder delivery melting/rapid solidification layer-by layer deposition [3]. The deposited layers are metallurgically bonded and exhibit a narrow heat-affected zone and small dilution zones, possessing a high accuracy and outstanding mechanical property [4]. Owing to the manufacturing principle and those significant merits, LCD technique is suitable for the repairing of defective components [5].

Repairing steel parts using LCD has been the subject of much research in recent years. Liu et al. $[4,6]$ presented a feasibility exploration of superalloys for AISI 4140 steel repairing using LENS. However, the tensile strength and hardness value of the specimens did not meet the industrial requirements. 
Liu et al. [5] applied the Taguchi method to optimize the process parameters of Fe-based self-fluxing alloy for the repair of an AISI 4140 sprocket using laser cladding. The repair accuracy of the sprocket could reach $2.973 \mathrm{~mm}$, and metallurgical bonding was realized between the cladding zone and the base metal. Marya et al. [7] demonstrated that the direct energy deposition repair of ferrous parts with UNS N06625 might restore damaged surfaces. Sun et al. [8] utilized laser cladding technology to repair 300M steel with 420 stainless steel powder and incorporated a laser idle time between each clad track to control the in situ quench and tempering sequence. It was found that the ductility was significantly improved. $\mathrm{Xu}$ et al. [9] applied simulation and experiments to study the remanufacturing process of a disabled thin-wall FV520B steel impeller blade with $\mathrm{Fe}-\mathrm{Cr}-\mathrm{Ni}-\mathrm{Cu}$ alloy powder using laser cladding, and defects like pores, cracks, or slag inclusions were not detected in the remanufactured region. Lewis et al. [10] assessed the wear and rolling contact fatigue performance of laser cladded-rail with four materials. The results showed that the rail cladded by 316 stainless steels did not deform under the cyclic loading applied and would offer a greatly enhanced rolling contact fatigue life. Lai et al. [11,12] investigated the effects of the cladding direction, preheating, and post-heat treatment on the microstructure and mechanical properties of laser cladding-repaired rail with 410L alloy. An excellent microstructural consistency was established across the railhead and its heat-affected zone.

Although many studies have been published concerning the restoration of the geometry and surface properties of steel parts, such as wear and erosion properties for laser cladding repair, [13], little attention has been paid to the mechanical properties of repaired steel components. The method of matching of the mechanical properties between the repair material and the substrate is important for the performance of the parts after repair. Meanwhile, the ability to join dissimilar metals represents a significant challenge due to the residual stresses [14], delamination [15], and intermetallic compounds, which might appear in LCD and render the material brittle [16]. 410L and Fe-Cr-B-Si-Mo alloys are both ferritic stainless steel and suitable cladding materials for the repairing of steel parts owing to their great metallurgical compatibility with steels [11,12] and excellent laser compatibility [15,17-20]. 410L alloy is widely used in automobile exhaust gas treatment devices and boiler combustion chambers because of its outstanding bending performance, ductility, high-temperature oxidation resistance. $\mathrm{Fe}-\mathrm{Cr}-\mathrm{B}-\mathrm{Si}-\mathrm{Mo}$ alloy is used for wear-resistant coatings of shafts due to its high toughness and crack resistance. However, the mechanical properties of the two alloys do not match those of most steels, such as AISI 5140 steel, AISI 1060 steel, and so on.

A large number of damaged steel parts have to be repaired every year. However, there are many kinds of steel. Each steel part needs to be repaired with one material, whose mechanical properties are similar to the mechanical properties of the steel part, limiting the development of the repair industry. The purpose of this paper is to present a new method for repairing varied kinds of steel with only two materials. The proposed method is to tailor the mechanical properties of ferrous alloys with a mixture of 410L and $\mathrm{Fe}-\mathrm{Cr}-\mathrm{B}-\mathrm{Si}-\mathrm{Mo}$ alloy powders via laser cladding deposition, such that the mechanical property meets the requirements of the steel parts. The microstructure and mechanical properties of the laser-deposited 410 L alloy with different concentrations of $\mathrm{Fe}-\mathrm{Cr}-\mathrm{B}-\mathrm{Si}-\mathrm{Mo}$ powder were investigated. Then, a case study of AISI 1060 steel repairing was implemented with the suitable powder, whose mechanical properties are similar to those of the substrate.

\section{Materials and Methods}

Gas-atomized 410L powder (Höganäs $\mathrm{AB}$, Höganäs, Sweden) with a particle size range of 53-150 $\mu \mathrm{m}$ and gas-atomized Fe-Cr-B-Si-Mo powder (BGRIMM Advanced Materials Science \& Technology $\mathrm{Co}_{0}$. Ltd, Beijing, China) with a particle size range of $45-105 \mu \mathrm{m}$ were employed in the present work. The morphologies of the 410L and Fe-Cr-B-Si-Mo powders are shown in Figure 1. The substrate used was AISI 5140 steel (Shandong Iron \& Steel Group Co., Ltd, Jinan, China), which was $150 \mathrm{~mm} \times 100 \mathrm{~mm} \times 10 \mathrm{~mm}$ in size. The chemical compositions are given in Table 1 . To investigate the effect of the concentration of $\mathrm{Fe}-\mathrm{Cr}-\mathrm{B}-\mathrm{Si}-\mathrm{Mo}$ powder on the microstructure and mechanical properties of the alloys, 5 kinds of powders, 410L, 410L $+6.25 \%$ Fe-Cr-B-Si-Mo, 410L + 12.5\% Fe-Cr-B-Si-Mo, 
410L $+25 \%$ Fe-Cr-B-Si-Mo, and Fe-Cr-B-Si-Mo, respectively named A1, A2, A3, A4, and A5, were prepared for LCD experiments.
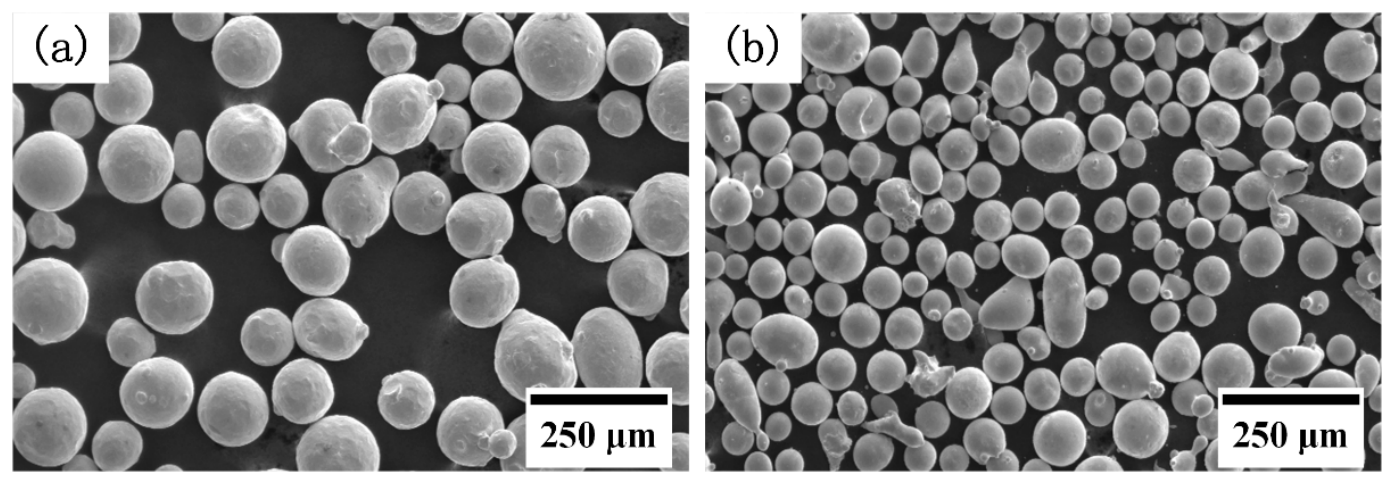

Figure 1. SEM micrographs of (a) 410L powder and (b) Fe-Cr-B-Si-Mo powder.

Table 1. Chemical composition of 410L, Fe-Cr-B-Si-Mo , and AISI 5140 and AISI 1060 steel alloys (wt \%).

\begin{tabular}{cccccccccc}
\hline Materials & Cr & B & Si & C & Mn & Mo & Ni & Cu & Fe \\
\hline 410L & 13 & - & 0.5 & 0.03 & 0.1 & - & - & - & Balance \\
Fe-Cr-B-Si-Mo & 13 & 1.6 & 1.2 & - & - & 0.8 & - & - & Balance \\
AISI 5140 & 0.80 & - & 0.25 & 0.40 & 0.80 & - & - & - & Balance \\
AISI 1060 & 0.25 & - & 0.27 & 0.61 & 0.65 & 0.1 & 0.25 & 0.25 & Balance \\
\hline
\end{tabular}

All the alloy samples were deposited using a homemade LCD system (Xi'an Jiaotong University, $X_{i}$ 'an, China) [21]. The schematic diagram of the LCD system is illustrated in Figure 2. The system fundamentally consists of a $1000 \mathrm{~W}$ Nd:YAG laser, a coaxial powder feed system, a gas shielded box, and a 3-axis motion control system. Argon was used as the powder carrier gas and shielding gas during the LCD process. The powder was uniformly mixed and dried, and the substrate surface was polished and cleaned by ethanol before the deposition. The optimized process parameters were employed, as shown in Table 2. The hatch path was set to an $\mathrm{S}$ shape, and the scanning direction of each layer was perpendicular to the previous layer. A rectangle sample of $15 \mathrm{~mm} \times 9 \mathrm{~mm} \times 5 \mathrm{~mm}$, and 3 cylindrical samples of $\Phi 8.2 \mathrm{~mm} \times 45 \mathrm{~mm}$ for each alloy were built via LCD.

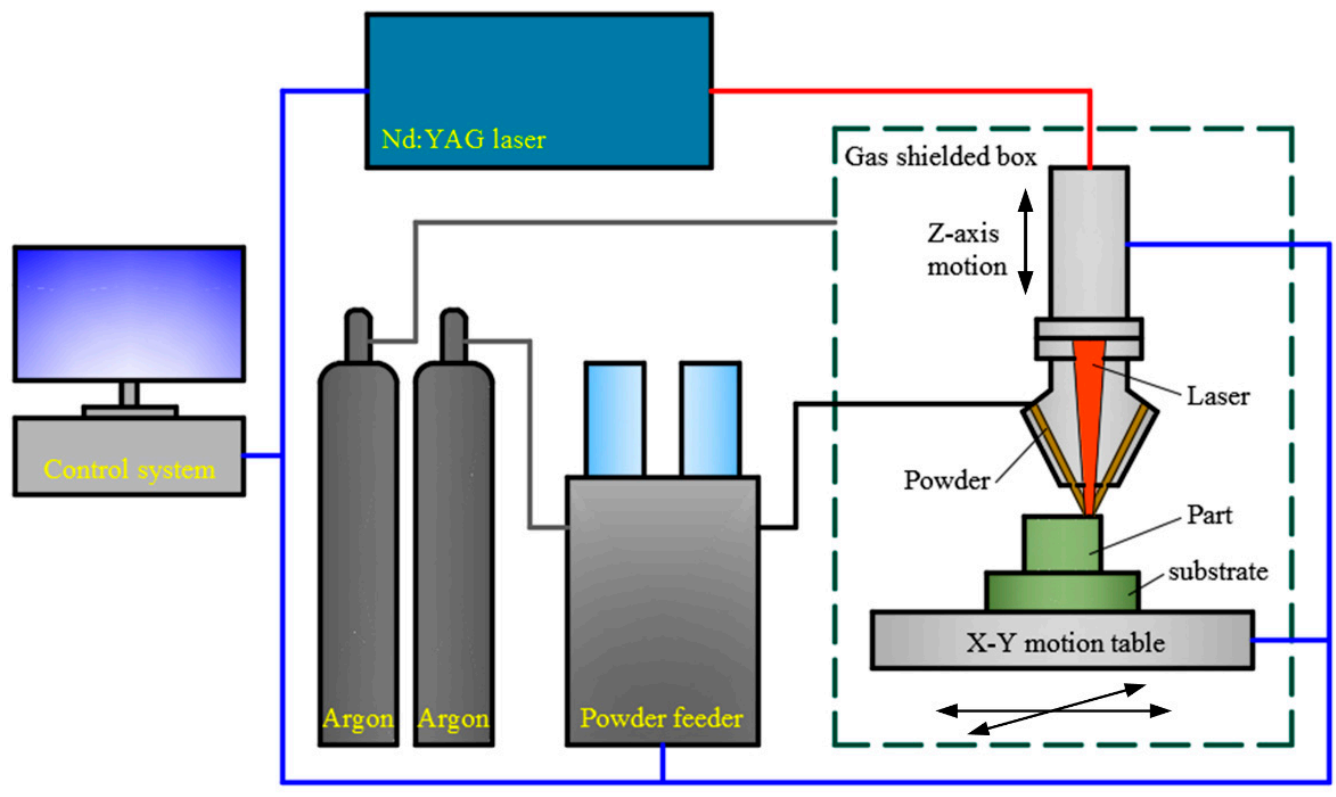

Figure 2. Schematic diagram of the laser cladding deposition (LCD) system. 
Table 2. Process parameters of laser cladding deposition.

\begin{tabular}{ccc}
\hline Process Parameter & Unit & Values \\
\hline Laser power & $\mathrm{W}$ & 180 \\
Scanning speed & $\mathrm{mm} / \mathrm{s}$ & 10 \\
Powder flow rate & $\mathrm{g} / \mathrm{min}$ & 4.5 \\
Spot diameter & $\mathrm{mm}$ & 0.5 \\
Hatch spacing & $\mathrm{mm}$ & 0.3 \\
Layer thickness & $\mathrm{mm}$ & 0.1 \\
\hline
\end{tabular}

The rectangle samples were sectioned vertically through the middle in length. The sections parallel and perpendicular to the building direction were mounted, grinded, and polished for metallographic observations and phase composition analysis, respectively. The metallographic specimens were then etched with a solution of $5 \mathrm{~g} \mathrm{CuCl}_{2}, 100 \mathrm{~mL} \mathrm{HCl}$, and $100 \mathrm{~mL}$ ethanol. The cylindrical samples were machined into dogbone-shaped tensile specimens with a gauge section of $20 \mathrm{~mm}$ (length) $\times 3 \mathrm{~mm}$ (diameter). The tensile tests were performed by an Instron 5985 tensile machine (Instron Corporation, Boston, America) at room temperature $\left(22^{\circ} \mathrm{C}\right)$. The etched metallographic specimens and the fracture surfaces of the tensile specimens were evaluated by a Hitachi SU-8010 scanning electron microscope (SEM, Hitachi, Ltd., Tokyo, Japan). The phase compositions of the sections, which were perpendicular to the building direction and were not etched, were identified by X-ray diffraction (XRD, Bruker AXS GmbH, Karlsruhe, Germany), using a Bruker D8 Diffractometer (Bruker AXS GmbH, Karlsruhe, Germany) with $\mathrm{Cu} \mathrm{K} \alpha$ radiation.

\section{Results and Discussion}

\subsection{Microstructural Evaluation}

Figure 3 shows the $\mathrm{X}$-ray diffraction patterns of the deposited alloys with different weight fractions of Fe-Cr-B-Si-Mo powder. From Figure 3, it can be noted that the peaks of ferrite/martensite (F/M) were all recorded in the pattern of the deposited alloys. Only the F/M peaks were observed in the pattern of the 410L alloy, as shown in Figure 3a, and the result is in agreement with the literature [11,12]. Figure $3 \mathrm{~b}-\mathrm{d}$ show the $\mathrm{X}$-ray diffraction patterns of the deposited alloys produced with a mixture of 410L and $\mathrm{Fe}-\mathrm{Cr}-\mathrm{B}-\mathrm{Si}-\mathrm{Mo}$ alloy powders. Compared with the patterns of 410L alloy, in addition to the peaks of $F / M$, the peaks of $\mathrm{Fe}_{2} B / \mathrm{Cr}_{2} B\left(\mathrm{M}_{2} \mathrm{~B}\right)$ were also recorded, the peak intensities of $\mathrm{M}_{2} \mathrm{~B}$ increased with the weight fraction of $\mathrm{Fe}-\mathrm{Cr}-\mathrm{B}-\mathrm{Si}-\mathrm{Mo}$ in $410 \mathrm{~L}$, which corresponded to the volume fraction of the $\mathrm{M}_{2} \mathrm{~B}$ phase increase. Figure $3 e$ shows the $\mathrm{X}$-ray diffraction patterns of the $\mathrm{Fe}-\mathrm{Cr}-\mathrm{B}-\mathrm{Si}-\mathrm{Mo}$ alloy. From Figure 3e, it can be observed that the peak intensities of $\mathrm{M}_{2} \mathrm{~B}$ were prominently higher than those of $\mathrm{F} / \mathrm{M}$, which suggests that the volume fraction of the $\mathrm{M}_{2} \mathrm{~B}$ phase may be more than that of the $\mathrm{F} / \mathrm{M}$ phase.

Figure 4 shows the microstructural characteristics of the $410 \mathrm{~L}$ alloy. From Figure 4 , it can be seen that there were large, elongated ferrite grains (dark color) and a small quantity of martensite grains (bright color), which were distributed along the ferrite grain boundary. This is due to the fact that during the transformation from austenite to ferrite, the ferrite nuclei form at the austenitic grain boundary and coarsen into the interior; meanwhile, the carbon diffuses into the austenite, which increases the austenitic carbon content and promotes the transformation of austenite to martensite. Although silicon was contained in the 410L alloy, no eutectic microstructure was observed.

A hypoeutectic microstructure was detected in the Fe-Cr-B-Si-Mo alloy, as shown in Figure 5. Fine ferrite grains occupy subordinately, while a eutectic microstructure consisting of ferrite and $\mathrm{M}_{2} \mathrm{~B}$ (bright color) dominated the alloy, and the volume fraction of the eutectic was greater than $50 \%$. This might be mainly attributed to the boron contained in the $\mathrm{Fe}-\mathrm{Cr}-\mathrm{B}-\mathrm{Si}-\mathrm{Mo}$ alloy; the boron exists in liquid near the liquid-solid interfaces during the solidification process due to its weak solubility in solid iron, which increases the constitutional undercooling of the remaining liquid, promotes the eutectic reaction [22], and restrains the growth of austenite grains. Meanwhile molybdenum contained 
in the $\mathrm{Fe}-\mathrm{Cr}-\mathrm{B}-\mathrm{Si}-\mathrm{Mo}$ alloy also acts to refine the austenite grains. Fine austenite grains eventually transform into fine ferrite grains during cooling.

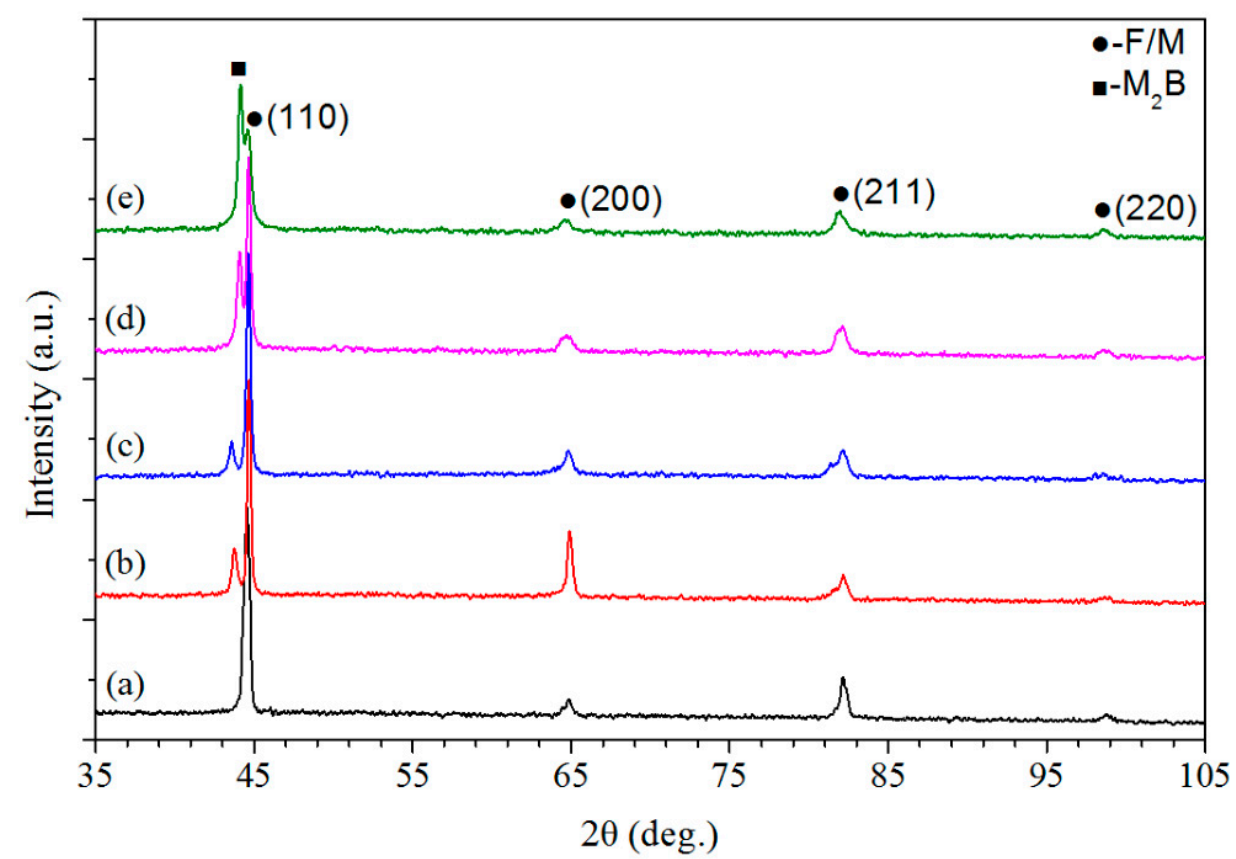

Figure 3. X-ray diffraction patterns of deposited alloys with different weight fractions of Fe-Cr-B-Si-Mo powder: (a) $0 \%$, (b) $6.25 \%$, (c) $12.5 \%$, (d) $25 \%$, and (e) $100 \%$, respectively.

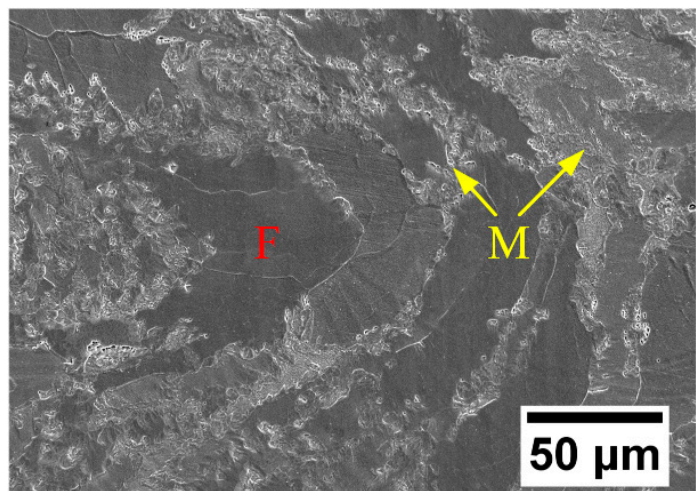

Figure 4. SEM micrograph of the deposited 410L alloy.
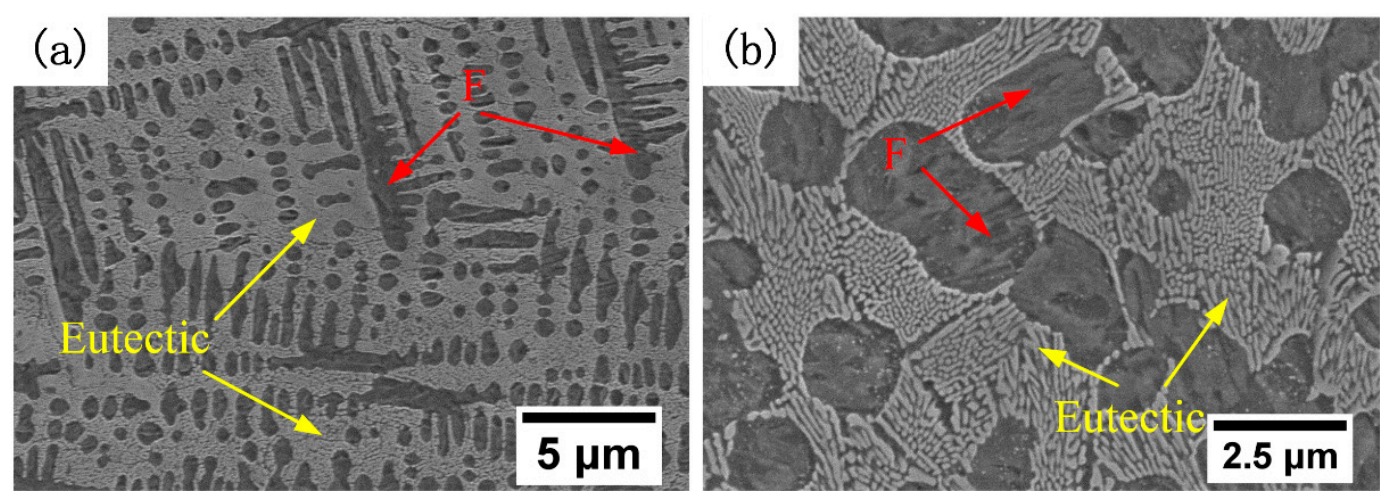

Figure 5. SEM micrographs of the deposited Fe-Cr-B-Si-Mo alloys. (a) Low- magnification; (b) high- magnification. 
Micrographs of a typical cross section of the deposited alloys with different concentrations of $\mathrm{Fe}-\mathrm{Cr}-\mathrm{B}-\mathrm{Si}-\mathrm{Mo}$ powder are shown in Figure 6. The diameter of the ferrite grains and the volume fraction of the eutectic in Figures 4-6 were calculated using ImageJ software, as shown in Figure 7. Fine ferrite grains and a small amount of interdendritic divorced eutectic were observed in the deposited 410L $+6.25 \% \mathrm{Fe}-\mathrm{Cr}-\mathrm{B}-\mathrm{Si}-\mathrm{Mo}$, as shown in Figure 6a. The size of the ferrite grains reduced to one-third of that of the 410L alloy (Figure 4). The ferrite grain size decreased, while the volume fraction of the eutectic increased with the increasing weight fraction of $\mathrm{Fe}-\mathrm{Cr}-\mathrm{B}-\mathrm{Si}-\mathrm{Mo}$ in the 410L alloy, as shown in Figure 7, and similar results were also observed in the literature [22]. This may be due to the fact that the liquid phase composition is closer to the eutectic composition as the boron content increases, so the volume fraction of the eutectic is larger, and the size of ferrite grains transformed from austenite is finer.
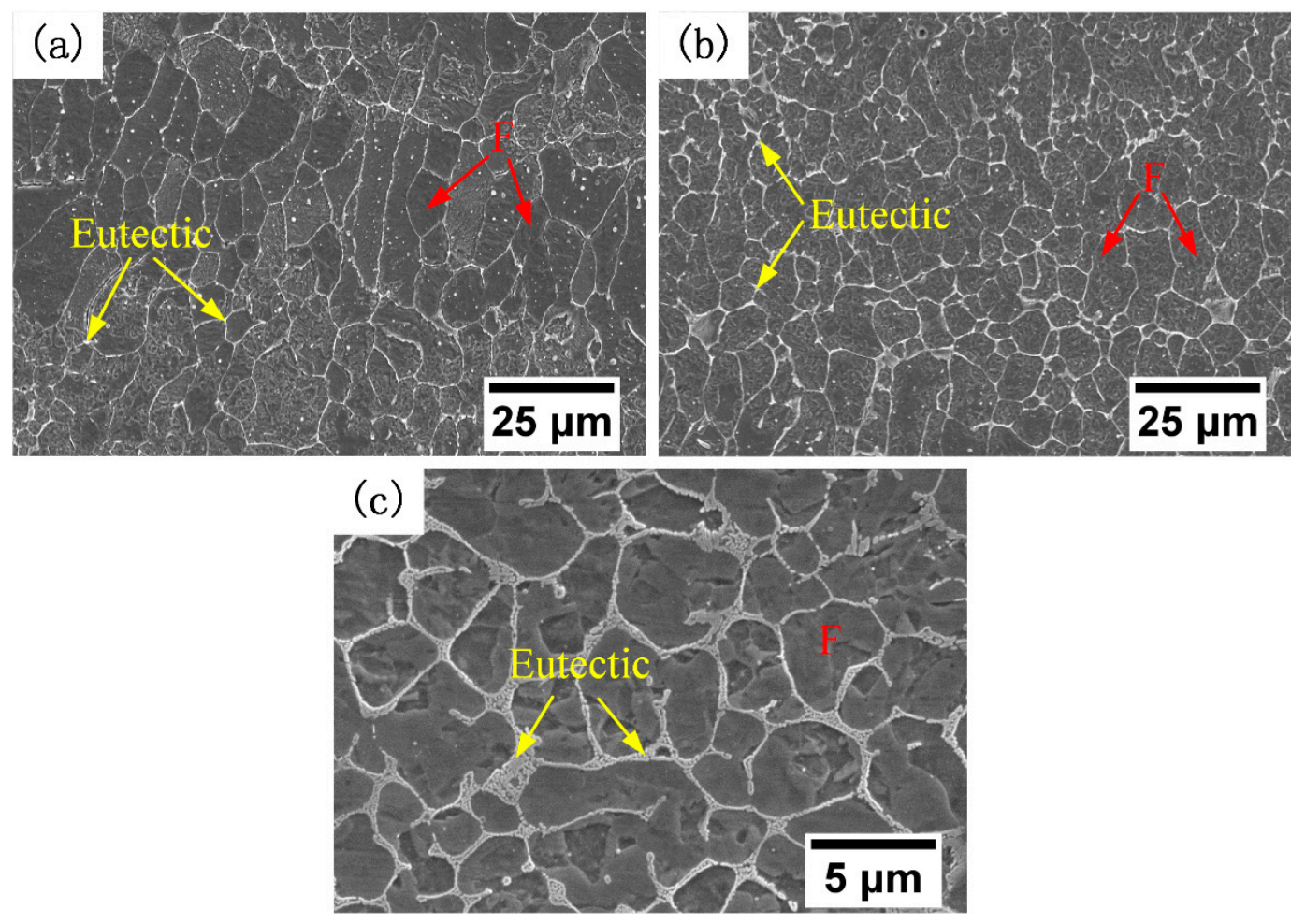

Figure 6. SEM micrographs of the deposited alloys at different concentrations of $\mathrm{Fe}-\mathrm{Cr}-\mathrm{B}-\mathrm{Si}-\mathrm{Mo}$ powder: (a) $6.25 \%$, (b) $12.5 \%$, and (c) $25 \%$, respectively.

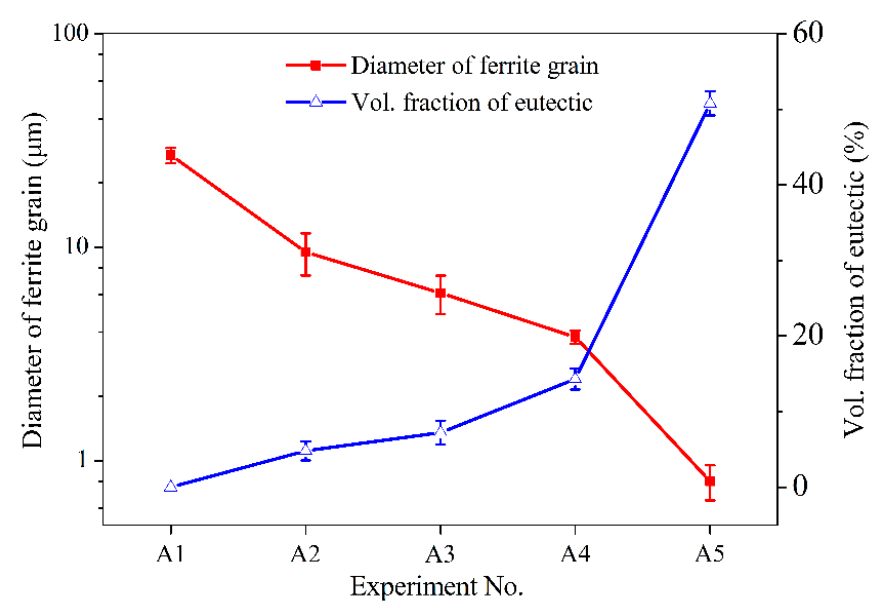

Figure 7. Diameter of ferrite grain and volume fraction of the eutectic in the deposited alloys at different concentrations of Fe-Cr-B-Si-Mo powder. 
Further, no martensite phase was observed in the deposited alloys containing Fe-Cr-B-Si-Mo alloy, as shown in Figures 5 and 6. To illustrate this phenomenon, the Schaeffler diagram was adopted, as shown in Figure 8. The chemical composition of ferritic stainless-steel elements (except Fe) are simplified by the chromium equivalent $\left(C r_{e q}\right)$ and nickel equivalent $\left(N i_{e q}\right)$, and the $C r_{e q}$ and $N i_{e q}$ are shown below:

$$
\begin{gathered}
C r_{e q}=\mathrm{Cr}+\mathrm{Mo}+1.5 \mathrm{Si}+0.5 \mathrm{Nb} \\
\mathrm{Ni}_{e q}=\mathrm{Ni}+30 \mathrm{C}+0.5 \mathrm{Mn}
\end{gathered}
$$

where each chemical element symbol indicates the percentage content [23]. Ferrite and martensite distribution in each alloy can be found in the Schaeffler diagram, except for the 410L alloy (A1); the other alloys (A2-A5) are located in the ferrite region of the Schaeffler diagram due to the content of carbon and manganese decreasing when the Fe-Cr-B-Si-Mo alloy was mixed into the 410L alloy.

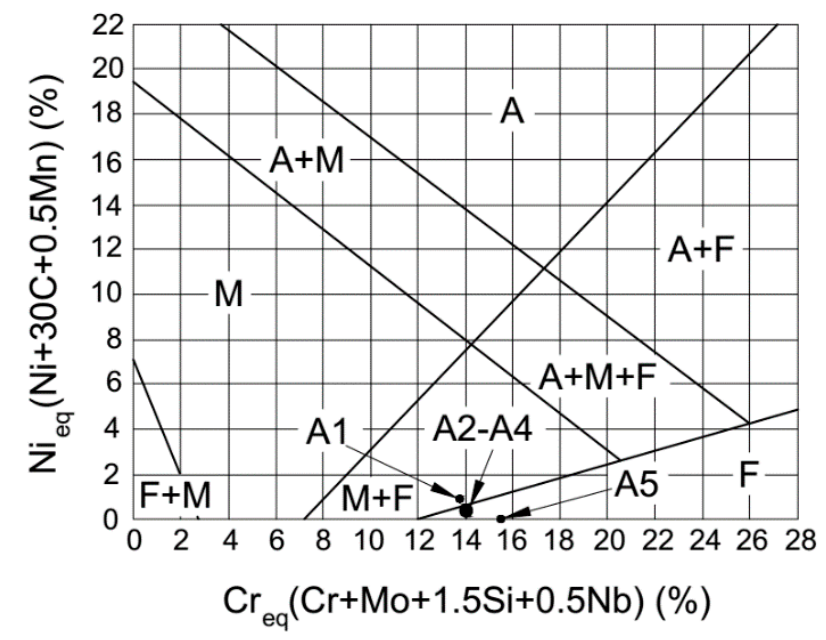

Figure 8. Ferrite and martensite distribution of the deposited samples on the Schaeffler diagram.

\subsection{Tensile Properties}

Figure 9 shows the stress-strain curves of the 410L alloy and Fe-Cr-B-Si-Mo alloy. From Figure 9, it can be observed that the yield strength (YS), ultimate tensile strength (UTS), and elongation of 410L alloy were $330 \mathrm{MPa}, 545.5 \mathrm{MPa}$, and 18\%, respectively, and the excellent tensile properties were attributed to its microstructure composed of ferrite and martensite. The YS, UTS, and elongation of the Fe-Cr-B-Si-Mo alloy were $841.5 \mathrm{MPa}, 1365.5 \mathrm{MPa}$, and $\%$, respectively, and the high strength and low plasticity were due to the eutectic microstructure. The tensile results of the deposited alloys with different weight fractions of Fe-Cr-B-Si-Mo powder are shown in Figure 10. In Figure 10, as the mass fraction of Fe-Cr-B-Si-Mo mixed in the 410L alloy increases, the YS and UTS increases from $282 \mathrm{MPa}$ to $1153.3 \mathrm{MPa}$ and from $565 \mathrm{MPa}$ to $1326.7 \mathrm{MPa}$, respectively, and the elongation decreases from $22 \%$ to $5.5 \%$. This is related to the aforementioned changes in the microstructure of the alloys; the strength of the alloy is improved because of the ferrite grain refinement according to the Hall-Petch strengthening behavior and the increasing volume fraction of the eutectic, while the plasticity is reduced due to the increasing numbers of the eutectic. 


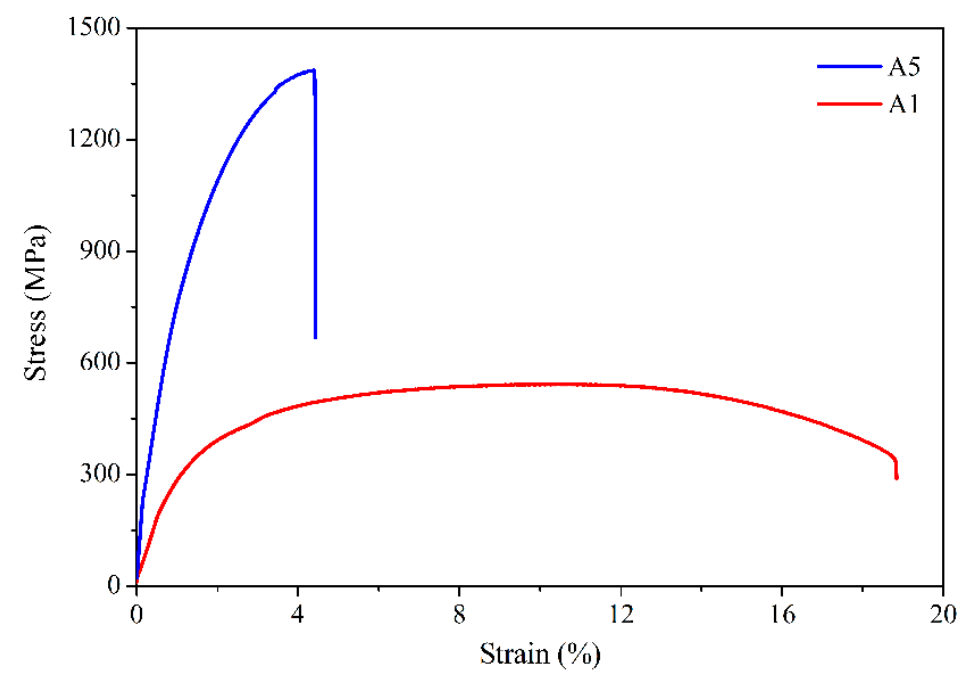

Figure 9. Stress-strain curves of the deposited 410L alloy and Fe-Cr-B-Si-Mo alloy specimens.

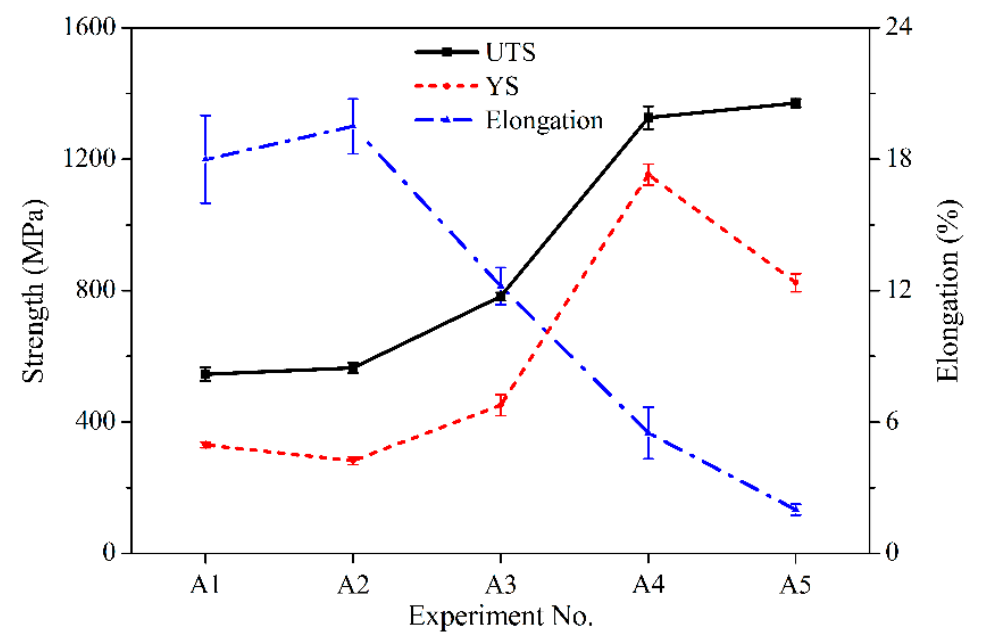

Figure 10. Ultimate tensile strength, yield strength, and elongation of deposited alloys at different concentrations of Fe-Cr-B-Si-Mo powder.

The fracture surfaces were examined using SEM to investigate the different tensile properties of the alloys (Figure 11). The SEM analysis showed that the tensile fracture of the alloys changed from ductility fracture to cleavage fracture. Many fine dimples and microvoids were observed on the fracture surfaces of the 410L alloy (Figure 11a) and the 410L + 6.25\% Fe-Cr-B-Si-Mo alloy (Figure 11b), which indicated that the fracture surfaces were ductile, the ductile fractures were reasonably consistent with the high elongation of the 410L alloy and the $410 \mathrm{~L}+6.25 \% \mathrm{Fe}-\mathrm{Cr}-\mathrm{B}-\mathrm{Si}-\mathrm{Mo}$ alloy (Figure 10). Figure 11c presents the fracture surface of the $410 \mathrm{~L}+12.5 \% \mathrm{Fe}-\mathrm{Cr}-\mathrm{B}-\mathrm{Si}-\mathrm{Mo}$ alloy; it can be seen that fewer and shallower dimples existed on the fracture surface of the 410L $+12.5 \% \mathrm{Fe}-\mathrm{Cr}-\mathrm{B}-\mathrm{Si}-\mathrm{Mo}$ alloy compared with that of the $410 \mathrm{~L}$ alloy and the $410 \mathrm{~L}+6.25 \% \mathrm{Fe}-\mathrm{Cr}-\mathrm{B}-\mathrm{Si}-\mathrm{Mo}$ alloy. The fracture of the $410 \mathrm{~L}+25 \% \mathrm{Fe}-\mathrm{Cr}-\mathrm{B}-\mathrm{Si}-\mathrm{Mo}$ alloy was a mixture of quasi-cleavage fracture and ductile fracture (Figure 11d). The fracture of the $\mathrm{Fe}-\mathrm{Cr}-\mathrm{B}-\mathrm{Si}-\mathrm{Mo}$ alloy was observed to be in quasi-cleavage failure mode (Figure 11e). 

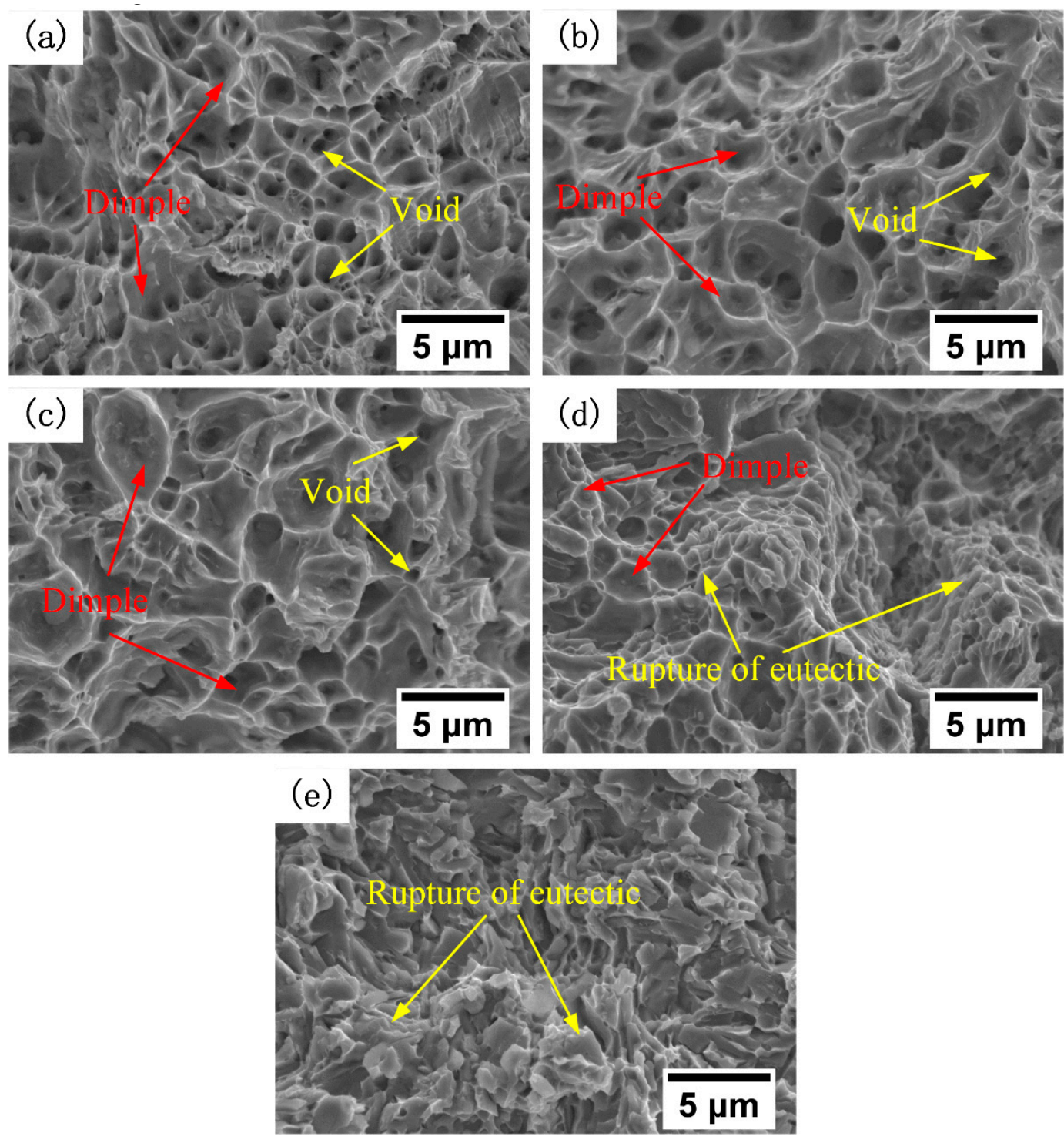

Figure 11. SEM micrographs of the fracture surface of deposited (a) 410L, (b) $410 \mathrm{~L}+6.25 \%$ Fe-Cr-B-Si-Mo, (c) 410L + 12.5\% Fe-Cr-B-Si-Mo, (d) 410L + 25\% Fe-Cr-B-Si-Mo, and (e) Fe-Cr-B-Si-Mo alloys, respectively.

\subsection{A Case Study of the Repair of AISI 1060 Steel}

The above research results showed that the mechanical properties of the deposited alloys could be adjusted by adding Fe-Cr-B-Si-Mo powder to the 410L alloy, which matched the mechanical properties of the steel that needed to be repaired. A case study of the repair of AISI 1060 steel (Table 1) was used to verify the feasibility of this method. AISI 1060 steel is a material used for railway wheels, which is usually worn and deformed by the complex contact between the wheels and rails, and the worn wheel is difficult to repair. The mechanical properties of AISI 1060 steel were close to those of the deposited 410L $+12.5 \%$ Fe-Cr-B-Si-Mo, so the 410L $+12.5 \%$ Fe-Cr-B-Si-Mo powder was chosen as the repair material, and three $410 \mathrm{~L}+12.5 \% \mathrm{Fe}-\mathrm{Cr}-\mathrm{B}-\mathrm{Si}-\mathrm{Mo}$ pillars (length of $25 \mathrm{~mm}$ and diameter of $8.2 \mathrm{~mm}$ ) were deposited onto the AISI 1060 steel substrate (dimensions of $75 \mathrm{~mm} \times 55 \mathrm{~mm} \times 40 \mathrm{~mm}$ ) (Figure 12a). Then, the specimen was machined onto the tensile samples. The size of the tensile samples is shown in Figure 12b. The mechanical properties of the AISI 1060 steel substrate samples, deposited $410 \mathrm{~L}+12.5 \% \mathrm{Fe}-\mathrm{Cr}-\mathrm{B}-\mathrm{Si}-\mathrm{Mo}$ samples, and 410L $+12.5 \% \mathrm{Fe}-\mathrm{Cr}-\mathrm{B}-\mathrm{Si}-\mathrm{Mo}$ for the AISI 1060 steel repairing samples are shown in Figure 13. From Figure 13, it can be noted that a YS of $406 \mathrm{MPa}$, an UTS of $794 \mathrm{MPa}$, and an elongation of $16.5 \%$ were obtained for the AISI 1060 steel substrate. Compared with 
the AISI 1060 steel substrate, the YS of the 410L + 12.5\% Fe-Cr-B-Si-Mo for AISI 1060 steel repairing was $449 \mathrm{MPa}$, about $110 \%$ of the YS of the substrate, the UTS was $801.5 \mathrm{MPa}$, slightly higher than that of the substrate, and the elongation was $16 \%$, about $97 \%$ of the elongation of the substrate, which indicated that the mechanical properties might meet the requirements for AISI 1060 steel repairing.

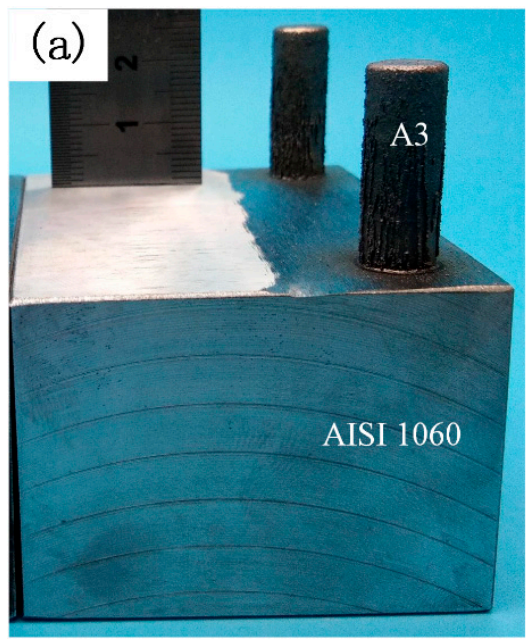

(b)

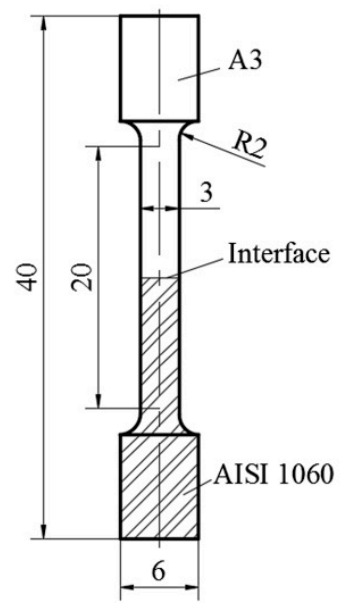

Figure 12. (a) Representative specimens after the $410 \mathrm{~L}+12.5 \% \mathrm{Fe}-\mathrm{Cr}-\mathrm{B}-\mathrm{Si}-\mathrm{Mo}$ was deposited onto the AISI 1060 steel substrate; (b) dimensions of the tensile samples of repair.

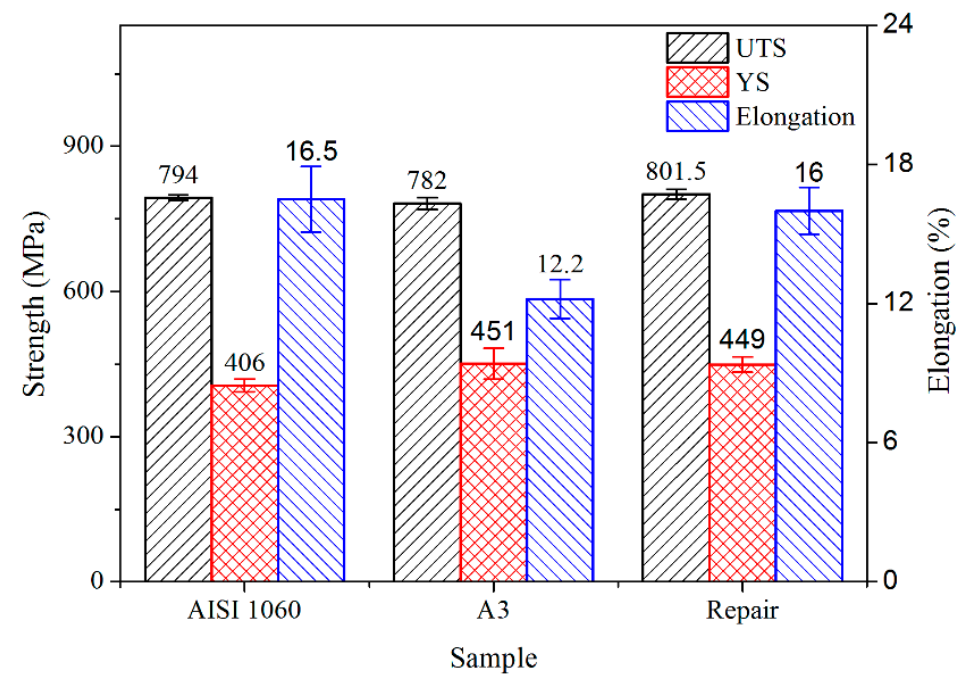

Figure 13. Comparison of the mechanical properties of the AISI 1060, 410L $+12.5 \%$ Fe-Cr-B-Si-Mo, and repair samples.

\section{Conclusions}

In this study, the microstructure features and mechanical properties of cladding with a mixture of 410L alloy and Fe-Cr-B-Si-Mo alloy powders were studied, and then, a case study of $410 \mathrm{~L}+12.5 \%$ Fe-Cr-B-Si-Mo repairing of AISI 1060 steel was implemented. The conclusions are as follows:

1. Coatings with several combinations of strength and plasticity were manufactured using LCD by adding different proportions of Fe-Cr-B-Si-Mo powder to 410L powder, which are available for the repair of various kinds of steel parts.

2. The microstructural morphologies of the deposited 410L alloy chiefly consisted of large, elongated ferrite grains and a small number of martensite grains distributed around the ferrite grain boundary, and it has low strength and good ductility. 
3. There were fine equiaxed ferrite grains and eutectic microstructures composed of ferrite and $\mathrm{Fe}_{2} \mathrm{~B} / \mathrm{Cr}_{2} \mathrm{~B}$ in the deposited $\mathrm{Fe}-\mathrm{Cr}-\mathrm{B}-\mathrm{Si}-\mathrm{Mo}$ alloy, and no martensite phases were observed. The alloy has high strength and low ductility.

4. With the increasing mass fraction of Fe-Cr-B-Si-Mo in the 410L alloy, the ferrite grains became finer, and the volume fraction of the eutectic increased. Moreover, the yield strength and ultimate tensile strength increased, and the elongation decreased.

5. AISI 1060 steel was successfully repaired by $410 \mathrm{~L}+12.5 \% \mathrm{Fe}-\mathrm{Cr}-\mathrm{B}-\mathrm{Si}-\mathrm{Mo}$ via LCD, and the mechanical properties of the substrate + deposited alloy were similar to those of the AISI 1060 steel substrate. This shows that tailoring the mechanical properties of laser cladding-deposited alloys with a mixture of $410 \mathrm{~L}$ alloy and $\mathrm{Fe}-\mathrm{Cr}-\mathrm{B}-\mathrm{Si}-\mathrm{Mo}$ alloy powders for steel repairing is a feasible solution.

Author Contributions: Conceptualization, S.H. and D.L.; Data curation, S.H.; Formal analysis, S.H.; Funding acquisition, D.L.; Investigation, S.H.; Methodology, S.H. and L.Z.; Project administration, D.L.; Software, S.H.; Supervision, D.L. and L.Z.; Validation, D.L. and L.Z.; Visualization, S.H.; original draft preparation, S.H.; review and editing of the manuscript, S.H., D.L., X.Z., and W.Z.

Funding: This research was funded by the National Natural Science Foundation of China, grant no. 51505457; the National Science and Technology Major Project, grant no. 2017-VII-0008; the Key Research and Development Program of Shaanxi Province, China, grant no. 2018ZDXM-GY-059; the Open Fund of State Key Laboratory of Manufacturing Systems Engineering, China, grant no. SKLMS2016013; and the Fundamental Research Funds for the Central Universities, China.

Conflicts of Interest: The authors declare no conflicts of interest.

\section{References}

1. Sun, S.D.; Leary, M.; Liu, Q.; Brandt, M. Evaluation of microstructure and fatigue properties in laser cladding repair of ultrahigh strength AerMet ${ }^{\circledR 100 ~ s t e e l . ~ J . ~ L a s e r ~ A p p l . ~ 2015, ~ 27, ~ S 29202 . ~[C r o s s R e f] ~}$

2. Griffith, M.L.; Schlienger, M.E.; Harwell, L.D.; Oliver, M.S.; Baldwin, M.D.; Ensz, M.T.; Essien, M.; Brooks, J.; Robino, C.V.; Smugeresky, J.E.; et al. Understanding thermal behavior in the LENS process. Mater. Des. 1999, 20, 107-113. [CrossRef]

3. He, B.; Tian, X.J.; Cheng, X.; Li, J.; Wang, H.M. Effect of weld repair on microstructure and mechanical properties of laser additive manufactured Ti-55511 alloy. Mater. Des. 2017, 119, 437-445. [CrossRef]

4. Liu, Z.; Cong, W.; Kim, H.; Ning, F.; Jiang, Q.; Li, T.; Zhang, H.C.; Zhou, Y. Feasibility Exploration of Superalloys for AISI 4140 Steel Repairing using Laser Engineered Net Shaping. Procedia Manuf. 2017, 10, 912-922. [CrossRef]

5. Liu, H.M.; Hu, Z.Q.; Qin, X.P.; Wang, Y.L.; Zhang, J.; Huang, S. Parameter optimization and experimental study of the sprocket repairing using laser cladding. Int. J. Adv. Manuf. Technol. 2017, 91, 3967-3975. [CrossRef]

6. Kim, H.; Cong, W.; Zhang, H.C.; Liu, Z. Laser Engineered Net Shaping of Nickel-Based Superalloy Inconel 718 Powders onto AISI 4140 Alloy Steel Substrates: Interface Bond and Fracture Failure Mechanism. Materials 2017, 10, 341. [CrossRef]

7. Marya, M.; Singh, V.; Hascoet, J.Y.; Marya, S. A Metallurgical Investigation of the Direct Energy Deposition Surface Repair of Ferrous Alloys. J. Mater. Eng. Perform. 2018, 27, 813-824. [CrossRef]

8. Da Sun, S.; Fabijanic, D.; Barr, C.; Liu, Q.C.; Walker, K.; Matthews, N.; Orchowski, N.; Easton, M.; Brandt, M. In-situ quench and tempering for microstructure control and enhanced mechanical properties of laser cladded AISI 420 stainless steel powder on 300M steel substrates. Surf. Coat. Technol. 2018, 333, 210-219. [CrossRef]

9. Xu, L.; Cao, H.J.; Liu, H.L.; Zhang, Y.B. Study on laser cladding remanufacturing process with $\mathrm{FeCrNiCu}$ alloy powder for thin-wall impeller blade. Int. J. Adv. Manuf. Technol. 2017, 90, 1383-1392.

10. Lewis, S.R.; Lewis, R.; Fletcher, D.I. Assessment of laser cladding as an option for repairing/enhancing rails. Wear 2015, 330, 581-591. [CrossRef] 
11. Lai, Q.; Abrahams, R.; Yan, W.Y.; Qiu, C.; Mutton, P.; Paradowska, A.; Soodi, M. Investigation of a novel functionally graded material for the repair of premium hypereutectoid rails using laser cladding technology. Compos. Part B-Eng. 2017, 130, 174-191. [CrossRef]

12. Lai, Q.; Abrahams, R.; Yan, W.Y.; Qiu, C.; Mutton, P.; Paradowska, A.; Fang, X.Y.; Soodi, M.; Wu, X.H. Effects of preheating and carbon dilution on material characteristics of laser-cladded hypereutectoid rail steels. Mater. Sci. Eng. A 2018, 712, 548-563. [CrossRef]

13. Sun, S.D.; Liu, Q.C.; Brandt, M.; Luzin, V.; Cottam, R.; Janardhana, M.; Clark, G. Effect of laser clad repair on the fatigue behaviour of ultra-high strength AISI 4340 steel. Mater. Sci. Eng. A 2014, 606, 46-57. [CrossRef]

14. Dong, Z.Q.; Zhang, J.X. Three-dimensional finite element analysis of residual stresses in circumferential welds of 2205/X65 bimetallic pipe. Int. J. Adv. Manuf. Technol. 2018, 96, 2841-2851. [CrossRef]

15. Espana, F.A.; Balla, V.K.; Bandyopadhyay, A. Laser surface modification of AISI 410 stainless steel with brass for enhanced thermal properties. Surf. Coat. Technol. 2010, 204, 2510-2517. [CrossRef]

16. Champagne, V.; Kaplowitz, D.; Champagne, V.K.; Howe, C.; West, M.K.; McNally, B.; Rokni, M. Dissimilar metal joining and structural repair of ZE41A-T5 cast magnesium by the cold spray (CS) process. Mater. Manuf. Process. 2018, 33, 130-139. [CrossRef]

17. Krishna, B.V.; Bandyopadhyay, A. Surface modification of AISI 410 stainless steel using laser engineered net shaping (LENS (TM)). Mater. Des. 2009, 30, 1490-1496. [CrossRef]

18. Kose, C.; Kacar, R. The effect of preheat \& post weld heat treatment on the laser weldability of AISI 420 martensitic stainless steel. Mater. Des. 2014, 64, 221-226.

19. Krakhmalev, P.; Yadroitsava, I.; Fredriksson, G.; Yadroitsev, I. In situ heat treatment in selective laser melted martensitic AISI 420 stainless steels. Mater. Des. 2015, 87, 380-385. [CrossRef]

20. Zhang, Y.J.; Yu, G.; He, X.L.; Ning, W.J.; Zheng, C.Y. Numerical and experimental investigation of multilayer SS410 thin wall built by laser direct metal deposition. J. Mater. Process. Technol. 2012, 212, 106-112. [CrossRef]

21. Lu, Z.L.; Li, D.C.; Lu, B.H.; Zhang, A.F.; Zhu, G.X.; Pi, G. The prediction of the building precision in the Laser Engineered Net Shaping process using advanced networks. Opt. Lasers Eng. 2010, 48, 519-525. [CrossRef]

22. Da Sun, S.; Fabijanic, D.; Ghaderi, A.; Leary, M.; Toton, J.; Sun, S.; Brandt, M.; Easton, M. Microstructure and hardness characterisation of laser coatings produced with a mixture of AISI 420 stainless steel and Fe-C-Cr-Nb-B-Mo steel alloy powders. Surf. Coat. Technol. 2016, 296, 76-87. [CrossRef]

23. Li, K.; Li, D.; Liu, D.; Pei, G.; Sun, L. Microstructure evolution and mechanical properties of multiple-layer laser cladding coating of 308L stainless steel. Appl. Surf. Sci. 2015, 340, 143-150. [CrossRef] 